\title{
José Parada y el sueño de una pintura científica en el siglo XIX español
}

\author{
Laura GonZÁlez MARTíneZ \\ Universidad Complutense de Madrid \\ Departamento de Historia del Arte (III) \\ laura.glez.mtez@hotmail.es
}

\section{RESUMEN}

Este ensayo tiene como objetivo presentar la historia de un concepto, el de pintura científica, a través de la figura de uno de sus máximos representantes en España: José Parada y Santín. Se atenderá tanto a la definición de este tipo de pintura, como a los materiales que se emplearon para su realización. Se valorará en su obra plástica el verdadero alcance de su propuesta teórica. Por último, a través de la producción de su alumno José Gutiérrez Solana desvelaremos cuál fue el paradójico final de la pintura científica.

Palabras clave: Pintura científica; Antropología Artística; José Parada y Santín; José Gutiérrez Solana.

\section{José Parada and the dream of a scientific painting in Nineteenth century Spain}

\begin{abstract}
The aim of this essay is the analysis of the development of the concept of "Scientific Painting" through one of its most representative Spanish figures: José Parada y Santín. His theoretical framework and methodology will be considered. Moreover, an evaluation of his real achievement of his theory through his painting will be carried out. Finally, an analysis of his disciple's art work José Gutiérrez Solana will allow us to reveal the paradoxical end of the Scientific Painting.
\end{abstract}

Key words: Scientific Painting; Spanish Ninetheenth Century Painting; Artistic Anthropology; José Parada y Santín; José Gutiérrez Solana. 


\section{JOSÉ PARADA Y SANTÍN Y EL SUEÑO DE UNA PINTURA CIENTÍFICA EN EL SIGLO XIX ESPAÑOL}

José Parada y Santín (1857-1923) ${ }^{1}$ fue un personaje relativamente conocido en el ambiente cultural del Madrid de entre siglos. Al finalizar sus estudios de medicina, ingresó en la Escuela Superior de Bellas Artes y tras una breve estancia en París, ocupó la cátedra de Anatomía Artística en la Escuela Superior de Pintura, Escultura y Grabado en 1884. Desde su posición de profesor y a través de sus numerosas colaboraciones en prensa (El liberal, La ilustración española y americana, El Globo, entre otras) divulgó su revolucionaria teoría: la creación de un arte científico. La conciliación entre lo científico y lo artístico fue un anhelo constante a lo largo de todo el siglo XIX especialmente desde el ámbito de la Anatomía Artística, siendo Parada uno de los primeros en articular un discurso sobre la cuestión de forma coherente y explícita.

Su doble formación, como médico y pintor, le condujo desde muy temprana edad a investigar las relaciones existentes entre el arte y la ciencia. Su tesis La medicina $y$ las Bellas Artes $(1877)^{2}$ supuso una primera aproximación al tema, enfatizando la utilidad del dibujo y de la escultura para los estudios naturales. Años después y de forma complementaria publicaría su Tratado de Anatomía artística o Antropología pictórica (1894) que, precisamente, apuntaba la utilidad que los descubrimientos científicos podían aportar al arte y, en concreto, a la pintura. En este último libro, que es el resultado de largos años de reflexión y docencia, desarrolla su teoría de la pintura científica.

Pero antes de abordar el tema propiamente dicho de este ensayo, me gustaría dar unas pinceladas sobre su polifacética personalidad. Además de los casi cuarenta años que dedicó a la docencia (1884-1922) y durante los cuales sus clases siempre estuvieron llenas, Parada y Santín fue un activo promotor de la inserción de la mujer en las enseñanzas artísticas. Prueba de ello, es la aceptación en 1886 de la asistencia de alumnas a sus clases (en una asignatura tan importante para la realización de cuadros figurativos como es la anatomía artística) ${ }^{3}$, así como el apoyo a favor de la participación de las mujeres para opositar a los premios de Roma ${ }^{4} \mathrm{y}$ la destacable colaboración femenina en las páginas de su revista: Para Todos (1902-1903).

Como pintor, obtuvo varias medallas en las Exposiciones Nacionales y participó en las muestras celebradas en el Círculo de Bellas Artes de Madrid o en la Exposición Internacional de San Francisco (1915). Dentro de la Academia, además de su cátedra, fue en varias ocasiones Secretario General de la Escuela y miembro jurado para la pensión de Pintura en Roma. Por otro lado, Parada y Santín gozó de cierta notoriedad social relacionándose con personalidades relevantes del momento como Cánovas del Castillo, músicos como Vital Aza o frecuentando los salones de Colombine. Como

1 Este ensayo está basado en mi trabajo de mi investigación: El sueño de una pintura científica. José Parada y los tratados de Anatomía artística en el siglo XIX.

2 Memoria presentada para los ejercicios del doctorado. Manuscrito conservado en la Facultad de Medicina de la U.C.M.

3 Archivo de la Academia de la Escuela de Bellas Artes de la U.C.M. (Caja 103)

4 PARADA Y SANTÍN, José, "La mujer y el arte" en El liberal, 10 de Mayo, 1901 y "Las mujeres en las oposiciones a Roma” en Para Todos, n² 21, 22 de Mayo, 1903. 
médico, fue un relevante higienista, defensor activo de la regeneración social, así como importante forense, amigo del anatomista Julián Calleja o del antropólogocriminal Rafael Salillas. Esta presencia tan notable en el contexto madrileño del momento determina que su obra teórica y artística fuera bastante conocida, mereciendo una atención especial para comprender un episodio particularmente desconocido de la pintura decimonónica española y que, sin embargo, le es tan propio al siglo como lo fue la fascinación que ejercieron los descubrimientos científicos en esta sociedad.

La pintura científica, tal y como se entendió desde la Academia, nació vinculada a una disciplina muy concreta: la anatomía artística. Ésta se introdujo en el sistema académico a finales del siglo XVIII por iniciativa de Rafael Mengs. Nacía al amparo de la teoría neoclásica y tenía como objetivo la correcta representación del cuerpo humano. A pesar de la vicisitudes iniciales, en 1843 el pintor Antonio $M^{a}$ Esquivel se hizo cargo de la asignatura adaptando eficazmente los contenidos de la misma a los intereses del alumnado. A partir de ese momento, los tratados reflejan la progresiva incorporación de modernas teorías de la Historia Natural que en apariencia rebasan el pretendido objetivo de la disciplina. Evidentemente, se seleccionó todo aquel material científico que se consideraba de utilidad para el artista y, teniendo en cuenta el carácter eminentemente visual de la Ciencia del XIX, fue mucho. La Antropología pictórica de Parada y Santín contiene básicamente los mismos contenidos que incluían sus predecesores en la materia, radicando la novedad de su aportación en el aparato teórico por él creado, es decir, el sistema que el autor articula a partir de ellos. Hasta cierto punto, podría considerarse que este médico-pintor lo único que hizo fue dar forma definitiva a una aspiración ya presente en los anteriores tratadistas dedicados a la cuestión: la posibilidad de crear una pintura científica.

¿Qué se entendió por pintura científica? Tal y como Parada y Santín la concibió, era aquélla que por medio de los recursos de la mímesis y siguiendo las conclusiones de las investigaciones científicas lograba la representación de la Verdad de las cosas. Por ello, la imagen artística debía aspirar a tener el mismo estatus epistemológico que la ilustración científica. Este estatus se lograría gracias al estudio que realizaba el artista sobre las cuestiones científicas de forma que, al realizar sus obras, sus imágenes trasmitieran conocimientos ciertos. Así, era ante todo una pintura dirigida al intelecto y no a los sentidos. En última instancia aspiraba a crear imágenes tan vivas como la vida misma, por ejemplo, usando los conocimientos sobre miología para transmitir la tensión vital del cuerpo humano.

Conviene profundizar en ciertos conceptos para que esta definición tenga pleno sentido. Es necesario puntualizar que la Verdad, tal y como la entiende Parada, es el resultado de la investigación científica. En el siglo XIX existió la creencia de que era posible un conocimiento certero de lo real, es decir, la sociedad participó de "la ilusión de que se había encontrado una clave de lo que realmente es"5. Esta clave, que no era otra que la derivada del optimismo ante los descubrimientos científicos, determinó que la Verdad descendiese del plano metafísico para identificarse con la verdad científica.

5 NOCHLIN, Linda, El realismo, Madrid, Alianza, 1991, p. 6. 
Pero ¿cómo era posible que la imagen artística reflejase las conclusiones de los experimentos científicos? Ya hemos avanzado que la ciencia decimonónica era sobre todo una ciencia visual y, en concreto, la antropología (que precisamente es la rama a la que Parada y Santín adscribe su propuesta) funcionaba a base de una catalogación de biotipos esencialmente visuales. La antropología había surgido con una pretensión totalizadora, esto es, como "ciencia racional del hombre" que buscaba abarcar todos sus aspectos (físicos, biológicos y culturales). Este enfoque naturalista determinó que los aspectos sociológicos y psicológicos fueran reducidos a una cuestión meramente biológica. Así mismo, el auge de determinados estudios como la fisiognomía o la craneoscopia tendieron a establecer una clara relación entre los elementos externos (los rasgos físicos) y los internos (las características psíquicas, intelectuales y morales) de los individuos. De esta forma, se codificó una interminable lista de signos visuales que connotaban esta u otra cualidad y que, además, explicaban los comportamientos sociales y culturales de los pueblos. Este catálogo de signos visuales que eran semánticamente significativos fueron empleados por Parada y Santín en sus clases con el objetivo de crear figuras verdaderas desde el punto de vista científico.

Estos biotipos surgieron como continuación de un sistema que la Ciencia había empleado desde la Antigüedad. La ilustración científica mostraba un modelo reductor y esencial con el objetivo de que otros investigadores pudieran al observar las láminas, reconocer el objeto de estudio. Si este dibujo era excesivamente detallista, se incurría en el peligro de que demasiado apegado al modelo, las diferencias entre los ejemplares de una misma especie no hicieran reconocibles el tipo esencial, perdiendo así su valor comunicativo y científico. De esta forma, cuando en el siglo XIX comenzaron a agruparse los individuos, se siguió este mismo sistema y se seleccionaron aquellas características que se creían comunes a un grupo racial o nacional, obviando las diferencias individuales. Estas ilustraciones gozaban del privilegio de la evidencia en la medida en que los conocimientos que trasmitían eran fácilmente comprobables en cualquier observación directa de la realidad. Parada y Santín demandaba precisamente esta evidencia propia de la ilustración científica para la imagen artística.

Así, el aprendiz al llegar a su clase aprendía los biotipos, memorizaba los rasgos físicos y sus significados (fig.1). Cuando más tarde este alumno tenía que enfrentarse al modelo real, su mirada estaba condicionada de antemano por los prototipos interiorizados. Este sistema no sólo permitía hacer imágenes "científicamente" verdaderas, sino que a la Academia le servía para mediatizar el estudio del natural, evitando que los artistas se apegasen excesivamente al modelo y salvaguardando de esta forma los cánones ideales de la figura humana defendidos por la institución.

Para evitar la monotonía, la anatomía artística elaboró un catálogo inmenso de rasgos fisionómicos (narices, ojos, formas de frente, cráneos, cejas) y de expresiones cada vez más matizadas (llanto dulce, llanto amargo, llanto desesperado...) con el objeto de que el artista tuviera los suficientes modelos a los que recurrir. En sí mismo este sistema estaba abocado al fracaso, en tanto que intentaba reducir toda la complejidad de la realidad a una serie limitada de tipos. Este intento de clasificar ad infinitum la variabilidad de formas de la realidad fue propio no sólo del arte, sino también de 

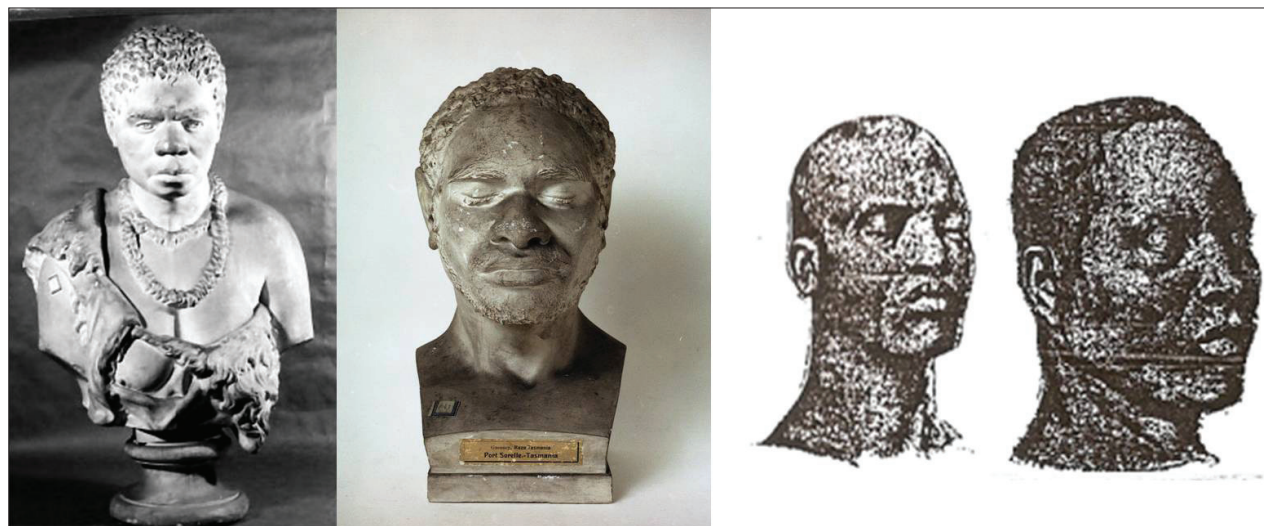

Fig. 1. Moldes del Museo Antropológico de Madrid (legado del doctor Velasco) y copias de los alumnos de Parada y Santín de moldes similares en su Tratado de Antropología pictórica, 1894, p.334.

la ciencia. ${ }^{6}$ Actitud que los caricaturistas del momento no dudaron en hacer objeto de sus burlas, a pesar de que éstos también se beneficiaron del potencial expresivo de los estudios fisionómicos en sus obras. (fig.2)

Por otro lado, si estos tipos se mostraban más o menos eficaces para la realización de escenas históricas o "temas modernos", no podían ser igualmente aplicables para la elaboración de retratos. Como el propio Parada y Santín evidencia en su tratado, existe una innegable tensión entre los tipos que propugnaba y el modelo concreto al que se enfrentaba en la realización de un retrato. Éste es, ante todo, la representación de una persona concreta y no de un tipo genérico. Y si es cierto que los biotipos científicos habían sido definidos a partir de las diferencias existentes respecto al modelo ideal de la especie humana: la imagen del hombre blanco (identificado con la figura de Apolo), se observa que con el objetivo de salvaguardar la individualidad del burgués, se apuesta por la observación directa del retratado sin preocupar, en este caso, más verdad que la del propio ojo del artista. Por todo ello, para resolver la imposibilidad de catalogar toda la variabilidad de las formas de la realidad, así como para mantener la individualidad de los burgueses, lo que Parada y Santín y sus coetáneos hicieron fue clasificar los rasgos y expresiones que se asociaban a todos los "excéntricos" de su discurso racial y social (negros, chinos, indios junto con delincuentes, enfermos mentales y obreros) siguiendo la tendencia del higienismo finisecular de "patologizar" determinados individuos de la sociedad.

La pintura científica también pretendía que el artista adoptase el método científico. Parada y Santín entendió que esta necesidad de experimentar sobe la realidad debía resolverse desde el ámbito del arte a través de las disecciones de cadáveres. Así, el artista conocía de primera mano el cuerpo humano, hacía sus mediciones con apara-

6 Starobinski ha denominado este conflicto a propósito de la Ciencia como tensión entre lo concéntrico y excéntrico en: STAROBINSKI, Jean, La invención de la libertad, Barcelona, Skira, 1964, p. 118. 


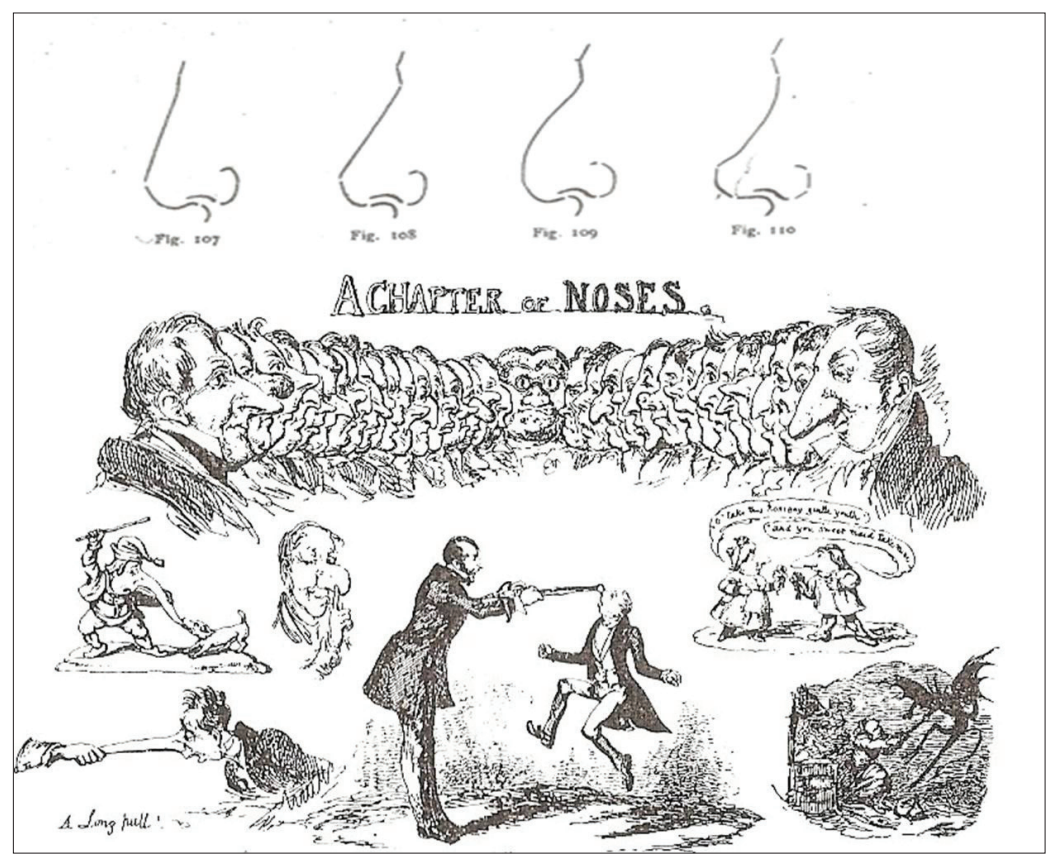

Fig. 2. Viñeta que evidencia el potencial de los estudios fisiognómicos para el caricaturista no sólo por la correspondencia entre rasgos físicos y psíquicos que éstos establecían, sino porque era un código con el que el público finisecular estaba bien familiarizado. (Abajo) George Cruishank en My sketch book (1833-36) [tomado de FEAVER, William, Master of caricature: from Hogarth and Gillray to Scarface and Levine, New York, Alfred A.Knopf, 1981, p.8] (Arriba). "Tipos de narices", en Anatomía y Fisiología para uso de los artistas de Tiberio Ávila, 1905-1914, Barcelona, Fidel Giró, vol. 2, p.34.

tos, tomaba sus propios apuntes y sacaba sus conclusiones. Sin embargo, esta actividad no tenía nada de método científico, al menos en lo concerniente a la actividad plástica.

Si analizamos las distintas estrategias de aproximación que existieron por parte de los artistas al ámbito científico, observamos una clara diferencia entre aquellos que adscritos al Realismo o el Impresionismo se sintieron realmente atraídos por ciertas características del método científico (imparcialidad, escrupulosa objetividad, exacta observación y notación de los fenómenos empíricos) ${ }^{7}$, frente a los académicos que asumieron las conclusiones y construcciones del discurso. Como Linda Nochlin su-

7 "Si bien los realistas no procedieron según los métodos de las ciencias naturales y no lograron entender las metas adecuadamente, sí compartieron, admiraron y quisieron imitar muchas de sus actitudes que determinaron en gran medida el carácter y la calidad de su obra: imparcialidad, impasibilidad, escrupulosa objetividad, rechazo de los prejuicios metafísicos o epistemológicos a priori, limitación por parte del artista a la precisa y exacta observación y notación de los fenómenos empíricos, y descripción del cómo y no por qué, acaecen los fenómenos." NOCHLIN, Linda, Op. Cit. p.13. 
giere, fue precisamente esta admiración hacia el método científico la que determinó que los artistas modernos buscaran un acercamiento sin prejuicios a la realidad, con la subsiguiente reivindicación de una mirada sincera y la valoración de la percepción sensorial en el fenómeno visual. En contraposición, la Academia, al estudiar los tipos genéricos del discurso científico, lograba, como ya hemos visto, justo lo contrario: mediatizar la mirada del artista en su estudio del natural y evitar extravíos de la teoría académica.

Como consecuencia de esta definición, la pintura científica era ante todo una pintura dedicada al intelecto. Hasta tal punto creía el médico-pintor que las imágenes artísticas podían llegar a ser imágenes objetivas y ciertas que no dudó en emplear éstas como documento científico a partir del cual se podían comprobar teorías médicas (por ejemplo, demostrando la teoría de la degeneración por las relaciones de consanguineidad mediante el estudio de los retratos de los Austrias), ${ }^{8} \mathrm{o}$ incluso considerando la obra artística como un material científico a partir del cual postular teorías científicas. En este sentido, ante la imposibilidad de la ciencia de definir un tipo nacional español, Parada propuso emplear los retratos del Prado siguiendo el sistema de Francis Galton, que consistía en la superposición de fotografías de diferentes individuos de un grupo de estudio en una misma placa con objeto de obtener "el tipo impersonal". Este uso de la pintura supone asumir que la neutralidad de la mirada científica es equivalente a la mirada artística, expulsando al sujeto del acto de mirar, tanto en el artista como en el espectador de la obra. Igualmente, cuando aplica sus biotipos a la pintura, Parada y Santín propone una equivalencia entre la mirada médica-naturalista que lee los signos visibles del paciente-objeto de estudio con el del espectador de la obra artística que lee los signos visibles de la figura representada. Precisamente por esta equivalencia, su pintura fue considerada por algunos críticos como una "escritura con tinta de colores" ${ }^{10}$ ya que era necesario conocer las teorías antropológicas del momento para la completa comprensión de la obra.

La popularidad de la teoría de Parada y Santín se debió no sólo a la relativa novedad de la misma, sino al ambiente que fue capaz de crear en sus clases así como a la espectacularidad de medios y materiales empleados para sus explicaciones. Tras acceder por oposición a su cátedra, este doctor llevó a cabo una importante reforma tanto de los contenidos como de la metodología de la asignatura. ${ }^{11} \mathrm{~A}$ su llegada se encontró que los alumnos básicamente se dedicaban a la copia de láminas de detalles anatómicos, práctica que consideró insuficiente e incluso negativa para la comprensión del cuerpo humano. Para solventarlo, incluyó en el programa de la asignatura las prácticas disectivas en el Colegio de San Carlos, las visitas al Museo de Antropología y los estudios anatomizados de estatuas y del natural. Así mismo, sus explicaciones

8 PARADA Y SANTÍN, José, Anatomía pictórica. Ensayo de Antropología artística, Madrid, Librería de la viuda de Hernando y compañía, 1894, p. 345.

9 Ibíd. "De la semejanza en la conformación de los individuos de una misma familia, de un mismo oficio o raza" Cap. XIII. pp. 231-233.

10 FERNANFLOR, "Exposición nacional de Bellas Artes", en La ilustración española y americana, 8 de Julio, 1887 , p. 7.

11 Libro de Actas de Junta de profesores, 12 de Febrero de 1885, Archivo de la Facultad de Bellas Artes de la U.C.M de Madrid. (Cajas 176 y 123). 
se acompañaron siempre del estudio de moldes, diapositivas a color y fotografías. Todo ello unido a su amena oratoria y moderna pedagogía (permitía a los alumnos decidir a quién conceder los premios de la asignatura) atrajo a numerosos jóvenes, algunos de los cuales ni siquiera estaban matriculados en sus clases. Una antigua alumna, Rosa Chacel, las recordaba así: "el profesor, el maestro, porque era él el que creaba en la Escuela un clima académico, no por normativo, sino por sugestivo. El creaba su mundo de academia, en su jardín de pájaros, primates, modelos vivos, láminas y signos, rasgos faciales trazados con tiza en el encerado: su clima era una irregularidad fluyente en la cátedra-nunca sobre la tribuna- siempre deambulando por entre los alumnos (...) Sus palabras (...) sus diálogos imprevisibles y siempre directos, siempre dedicados a la persona, al que respondía-nunca obligatoria respuesta discipular". ${ }^{12}$

No podemos profundizar aquí en el contenido de las clases, sin embargo sí me parece interesante destacar algunos aspectos. Se ha señalado que las visitas al Museo de Antropología estaban incluidas en el programa. Este museo estaba repleto de moldes de tipos étnicos, esqueletos, figuras de cera, frascos con extraños fetos y malformaciones. Parada los llevaba allí, les permitía copiar, analizar, estudiar de forma directa y práctica los estudios de Petrus Camper, Lavater y tantos otros. Así mismo, para el análisis de las expresiones mostraba las todavía hoy sorprendentes fotografías de Duchenne de Boulougne y de Charles Darwin. Para la cuestión del movimiento, enfatizaba el estudio en vivo de la anatomía y mostraba cronofotografías. Atraídos por la novedad, los alumnos se familiarizaban con las fotografías de "tipos" de Jean Laurent, así como entraban en contacto con los estudios sobre criminales y prostitutas de nuestro Lombroso nacional: Rafael Salillas.

Es cierto que pocos alumnos se comprometieron en sentido estricto con la idea de la pintura científica, no obstante, consideraron estos materiales como herramientas útiles a la hora de realizar sus obras siendo fácilmente constatable, por ejemplo, el empleo de las fotografías científicas sobre las expresiones en sus producciones. Según acabamos de afirmar podría pensarse que, en sentido estricto, no hubo una "pintura científica" tal y como la hemos definido al principio. Sin embargo, no podemos obviar que el uso del material científico por parte de los artistas fue una constante a lo largo de todo el XIX. Así mismo, nos queda parte de la obra de Parada y Santín, la cual nos servirá para comprender por qué este nuevo tipo de pintura no pudo prosperar.

José Parada cultivó varios géneros pictóricos destacando especialmente en el retrato. A pesar de los reconocimientos oficiales que obtuvo, la calidad de su obra es bastante mediocre siendo puesta en tela de juicio no sólo por los críticos defensores de la modernidad en su época, sino incluso por los partidarios del eclecticismo oficial. ${ }^{13}$ En estas críticas se destaca frecuentemente su descuido de la perspectiva, la falta de

12 CHACEL, Rosa, Acrópolis, Barcelona, Seix Barral, 1984, pp. 26-27.

13 Algunas de estas críticas son: DE PALACIO, Eduardo, "Exposición de Bellas Artes. Sala E", en El Imparcial, n'. 6125, 19 de Junio de 1884. E.V.A., "Notas de arte. Parada y Santín", en El Globo. Diario independiente, 8 de Mayo de 1909. ALCÁNTARA, Francisco, "Notas de arte. Varias exposiciones", en El Imparcial, 20 de Mayo de 1909, p. 4. 
precisión en el dibujo y la inexpresividad de sus figuras. El realismo científico al que aspiraba Parada y Santín fracasó no sólo por su falta de pericia, sino porque el uso de sus tipos codificados a priori derivó en la realización de figuras estereotipadas y poco naturales. No obstante, hemos de tener en cuenta que este artista siempre consideró la perfección técnica una cuestión secundaria, subordinando los aspectos formales a la legibilidad de las figuras. Como ya hemos comentado, sus figuras pueden "leerse" en clave antropológica-médica. El color, las formas o la actitud nunca son arbitrarios y las figuras se conforman a modo de una historia clínica visual. Además, es frecuente que realice representaciones donde el espectador pueda contrastar los tipos que representa. Así, en Los mejores amigos y Los peores amigos (fig. 3), dos obras que han de analizarse conjuntamente, se evidencian estas características. Si observamos atentamente, Parada busca crear el "tipo" del anciano por medio de un cuidadoso estudio de las arrugas, del fruncimiento de los labios, etc. En Los peores amigos presta especial atención al brillo acuoso de los ojos, a la rojez del rostro y a las cejas arqueadas, rasgos (signos visuales) asociados al estado de embriaguez y, por ende, del tipo "etílicamente intoxicado". En contraposición, Los mejores amigos muestran un anciano donde las arrugas son más rectas (asociadas al estado de atención) así como la boca y los pómulos trasmiten estabilidad y orden. En cierto sentido, puede afirmarse que los dos personajes, en realidad, son sólo uno y las diferencias que se presentan son el resultado del tipo de vida (viciosa o virtuosa) que han llevado.
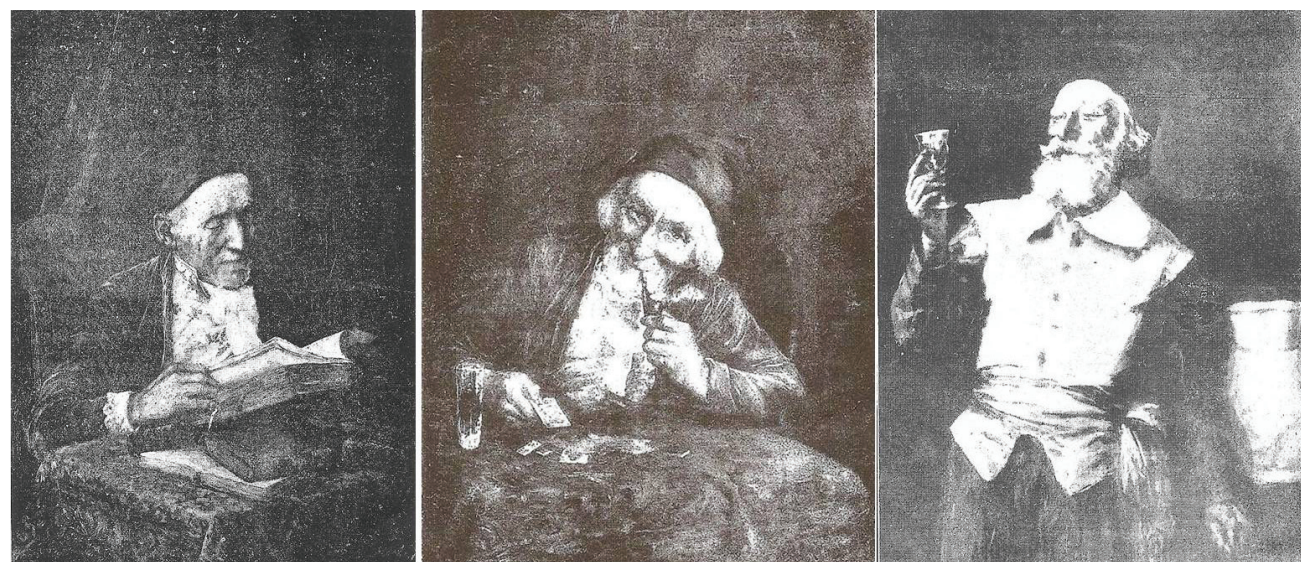

Fig. 3. PARADA y SANTÍN, José, Los mejores amigos. Los peores amigos. Brindis. Copias de los cuadros reproducidas en la revista Para Todos, ${ }^{\circ}$. 10, 14.

Otras obras parecen tener como objeto el estudio de una expresión, así Brindis (fig.3) lo sería de la felicidad y La Plegaria de la esperanza o de la preocupación en el acto de rezar. Si podemos aceptar que estas expresiones provienen del estudio científico de las mismas, no podemos negar que el efecto general es artificial. Es posible que al reírnos, nuestro rostro se contraiga de forma similar al personaje de Brindis, pero ello no evita que la imagen no resulte convincente y natural. La sensación gene- 
ral que se tiene en sus obras es la de que nos encontramos frente a figuras detenidas y congeladas, como si observásemos una instantánea tomada en un momento de la acción, siendo la imagen incapaz de trasmitir la sensación de dinamismo tal y como la percibimos en la realidad. Así, la captación de movimiento y sensación de vida que este artista busca transmitir en sus imágenes fracasa al intentar sintetizar en un solo gesto y postura tanta teoría y estudio científico.

En general, podemos afirmar que la teoría de José Parada supuso un obstáculo para que su obra sobresaliese, así como sus capacidades resultan demasiado modestas para llegar a tan elevadas pretensiones. Pero ¿la pintura científica finaliza con el estrepitoso fracaso de este pintor? Conviene apuntar un último aspecto sobre la modernidad de este tipo de pintura. Porque si bien fue especialmente conservadora en sus soluciones formales, el discurso era plenamente coetáneo a los intereses de la sociedad en la que surgió. El potencial moderno que entrañaba esta teoría y, en concreto, los materiales de los que sirvió fue explotado por uno de sus alumnos: José Gutiérrez Solana. Eso sí, subvirtiendo el sentido final de la "pintura científica", el de dotar de vida a las figuras representadas.

Hasta el momento, cuando se ha estudiado la obra de Solana se ha tendido a señalar que a pesar de su ingreso en la Academia de San Fernando, poco o nada pudo aprender entre las paredes de esta vetusta institución. Se ha indicado oportunamente que la única clase que atrajo su atención fue la del doctor Parada, debido a la predilección que sentía Solana hacia la anatomía. Pero al mirar sus cuadros nos asalta la duda: ¿Qué anatomía podía enseñarse en la Academia cuando sus personajes parecen muñecos de trapo?

Se podría pensar que a Solana de poco le serviría la corrección anatómica para la construcción de su personalísimo mundo de autómatas y muñecos. De esta forma, su interés hacia esta disciplina vendría justificado por su atracción morbosa hacia lo macabro. Sin embargo, lo que hemos apuntado a lo largo de estas páginas permite una nueva vía de interpretación.

El siglo XVIII, ante el avance de los descubrimientos tecnológicos, había soñado con la posibilidad de crear la vida. La fe en la ciencia despertó anhelos olvidados y la interpretación mecanicista del mundo sugirió la posibilidad de que, quizá, en algún futuro próximo, el hombre sería capaz de crear seres vivos por medio de la técnica. En el siglo XIX los autómatas habían pasado de moda pero este sueño siguió vigente proyectado, eso sí, hacia el ámbito de la medicina. En el arte, este anhelo resurgió también, siendo la anatomía artística la que asumió el reto. La pintura científica pretendió, en última instancia, aproximar la pintura a la vida, vivificar sus figuras haciéndolas reales. Para este fin, Parada codificó una serie de tipos "reales", llevó a sus alumnos a estudiar disecciones y moldes de cera. No es casual que, precisamente, desde el siglo XVIII fueran las figuras de cera los objetos predilectos en el estudio de la anatomía. Frente a las láminas, los moldes usaban el color didácticamente, presentaban el cuerpo en tres dimensiones y poseían una sensación de vida inquietante. 
Esta "sensación de inquietante extrañamiento" ${ }^{14}$, provocada por la incertidumbre cognoscitiva ante la confusión de lo orgánico y lo cosificado, fue explotada por el joven Solana posiblemente motivado por la fuerte sensación que provocaron en él las visitas al Museo de Antropología y a las salas de disección. Sobre estas visitas, el pintor dejó escritos varios relatos como Exposición de figuras de cera o La sala de disección. El descubrimiento de los moldes anatómicos fue un feliz hallazgo, casi una revelación, para el artista que se sintió especialmente atraído por las figuras de cera del s. XVIII que comentábamos anteriormente: "pero la vitrina que nos produce más emoción es la de un grupo de figuras de cera, de mitad del tamaño normal, que parecen personas vivas" ${ }^{15}$. Testimonio de estas visitas es la presencia de algunos de estos moldes en el retrato que Solana hizo de José Parada y Santín. Así mismo, fruto de esta sensación de extrañamiento son las dos obras tituladas Las vitrinas y El visitante y las vitrinas (1910). Sin embargo, las deudas de la obra de Solana respecto al maestro, van mucho más allá de estas y otras relaciones superficiales. Solana a través de la "resurrección" de las figuras de cera (dotar de vida a los objetos) y la cosificación de los seres vivos, está alterando la premisa primera de las anatomías artísticas.

Solana comenta: "Cuando he salido a la calle lo he visto, pero no lo he tomado así, como un reflejo del natural sino llegando al realismo" ${ }^{16}$. Un realismo que subyace tras la figura individual de cada uno de los seres que él contempla, una realidad esencialmente verdadera donde lo concreto se diluye en el tipo. ${ }^{17} \mathrm{Y}_{\text {¿cómo podríamos no- }}$ sotros obviar la relevancia que tenían los tipos, los tipos "verdaderos", para Parada y Santín? Cuando Solana acudió a las clases de la Academia prestó atención, y mucha, a las teorías de aquel viejo profesor.

El tipo era capaz de mostrar la verdad con una eficacia superior a la contingencia de lo concreto y, como lenguaje verdadero y esencial, era fácilmente comprensible. Si los visitantes de la Sala del crimen se mostraron tan reacios a las pinturas de Solana, no fue sólo por la imperfección acartonada de sus figuras, sino porque en ellos se revelaba sin nada anecdótico una realidad más profunda. Los cuadros de temática social, que gozaban de tanta popularidad, eran imágenes concretas y por ello precisamente podían entenderse como una excepción. Así, las imágenes de cruenta injusticia social permitían una lectura tranquilizadora y melodramática, salvaguardando la conciencia burguesa. Pero cuando Solana mostraba a sus desharrapados, prostitutas y paletos reflejaba la generalidad de estos tipos (los muchos individuos que había tras ellos) evitando cualquier tipo de lectura escapista. En este sentido, en Solana igual que en Parada y Santín existe una análoga identificación entre la verdad y el tipo aunque empleados en un sentido diferente. Pero ¿en base a qué podían considerarse los

14 Esta sensación o uhnheimliche fue definida por Freud precisamente a propósito de las figuras de cera y autómatas.

15 GUTIÉRREZ SOLANA, José, “La sala de disección”, en Madrid, escenas y costumbres. Segunda serie. (1918) en Obra literaria, Madrid, Fundación Santander, $3^{\circ}$ ed., 2004, p. 256.

16 SÁNCHEZ-CAMARGO, Manuel, Solana. Vida y Pintura, Madrid, Taurus, 1962.

17 Manuel Abril señalaba sobre esta misma cuestión: "La anécdota en los cuadros de Solana es lo de menos, si es que existe. En Solana no hay más que retratos: retratos de tipos, retratos de espectáculos, pero no narraciones de argumentos" en ABRIL, Manuel, "Solana ni es...", en De la naturaleza al espíritu. Ensayo crítico de pintura contemporánea desde Sorolla a Picasso, Madrid, Espasa Calpe, 1953 (1934). 
tipos de Solana verdaderos? En su caso, la verdad también procede de la antropología pero de una rama más específica y moderna: la antropología criminal.

Solana recurrió a las imágenes del libro La mala vida en Madrid: estudio psicosociológico con dibujos y fotografias (1901) para crear algunas de sus figuras (fig.4). ${ }^{18}$ El conocimiento de este libro por parte del artista se explica por la mediación de Ricardo Baroja, el cual había colaborado en la elaboración de éste. Sin rechazar dicha conexión, creo que, como ha quedado ya indicado en este ensayo, es muy posible que Solana estuviera al corriente de este tipo de estudios y fotografías a partir de las clases de anatomía, dada la relación existente entre Rafael Salillas y Parada.

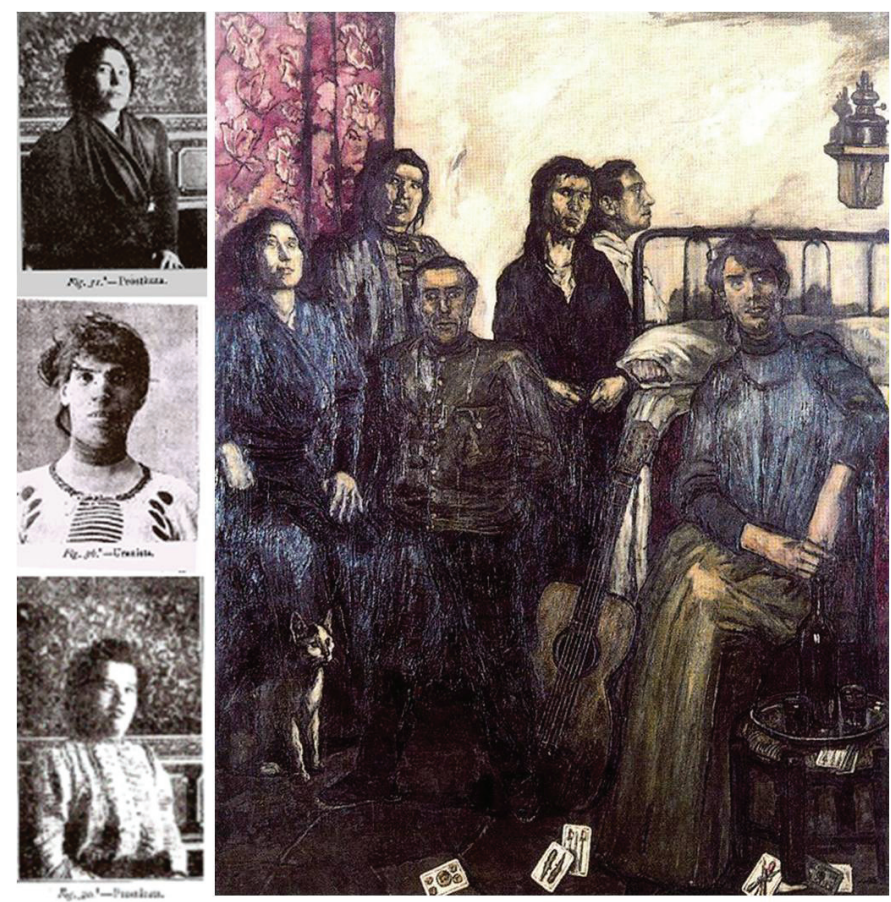

Fig. 4. Fotografías del libro La mala vida en Madrid (1901) de Bernaldo de Quirós empleadas por J. Gutiérrez Solana en la realización de Los caídos, 1915, óleo sobre tela, 208x160,5 cm., Museo Nacional de Bellas Artes de Buenos Aires, INV:2627 [tomado de http://lozzanoart.blogspot.com/2009/04/jose-gutierrez-solana.html].

No obstante, es necesario volver a incidir una vez más en una diferencia fundamental entre maestro y discípulo. Solana cosifica sus figuras, no intenta dotarlas de vida. Para ello, el estudio de las imágenes y fotografías antropológicas debieron resultar muy eficaces ya que estas imágenes muestran a los individuos cosificados. Si Parada

18 Relación establecida por ALONSO FERNÁNDEZ, Luis, “J. Solana. Estudio y Catalogación de su obra” en J. Solana, Madrid, Ayuntamiento de Madrid. 1985. 
y Santín fracasó en su intento de crear una pintura viva, en parte se debió al hecho de que todos los referentes elegidos eran, en el sentido literal del término, "objetos" de estudio. Por lo tanto, Solana sólo tuvo que eliminar aquellos elementos que Parada vinculaba con la vida interna y externa de los personajes, esto es, las expresiones y el movimiento. Muchos de los recursos que Solana usa provienen directamente de la fotografía antropológica, como ya señaló Jean Cassou en su momento: “coloca a sus personajes en fila, en la parte delantera del lienzo, como si se tratara de un grupo fotográfico. Los planta ahí, ingenuamente, junto con los atributos de su trabajo, su miseria o su locura. No hay nada de melodramático en sus actitudes. No están haciendo nada (...) Son brazos que cuelgan, cuerpos, rostros y objetos." ${ }^{19}$ Así mismo, sabemos que Solana era aficionado a la fotografía. Junto a fotos bizarras de seres monstruosos y muertos, guardaba fotografías de tipos regionales y campesinos (como las de Jean Laurent) algo pasadas de moda. La elección de estas imágenes anticuadas se debe, precisamente, a que éstas muchas veces poseen un carácter próximo al del documento etnológico: colocando los individuos frontalmente, rígidos y con la mirada fija.

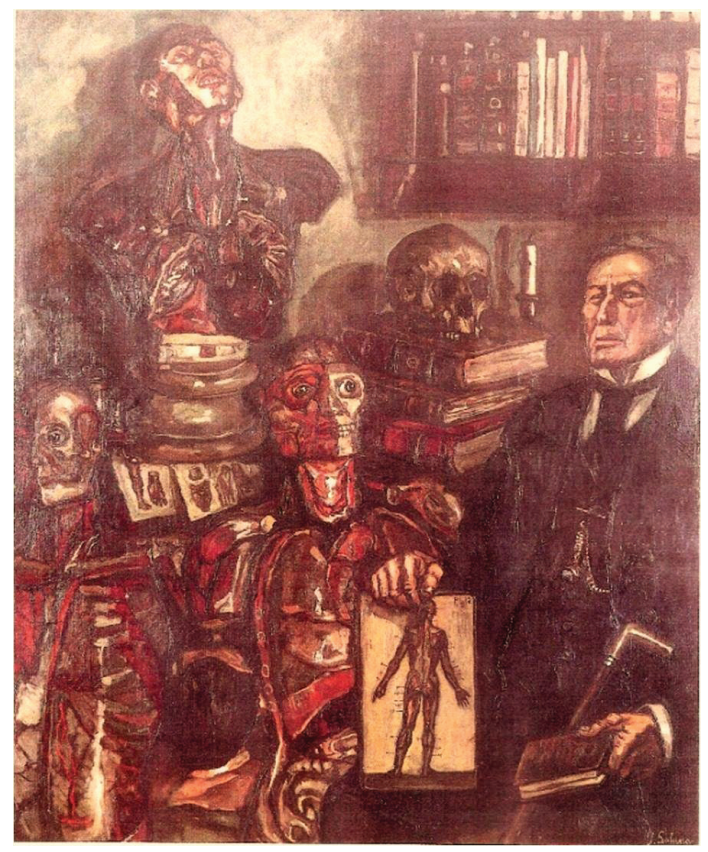

Fig. 5. J. Gutiérrez Solana, El maestro de anatomía, 1923, óleo sobre tela, 1,43x 1,18, Museo Nacional de Bellas Artes de Buenos Aires, cat. 285 [tomado de FERNÁNDEZ GARCÍA, Ana Ma . Catálogo de pintura española en Buenos Aires, Universidad de Oviedo Servicio de Publicaciones, 1997, p.90].

19 CASSOU, Jean, “José Gutiérrez Solana”, en L'Art et les artistas, n 7621, Abril, 1927, pp. 232-237. Recogido en A.A.V.V. José Gutiérrez Solana, catálogo de exposición, (Madrid, 2004), Madrid, Museo Nacional Centro de Arte Reina Sofía, (9 de Marzo- 24 de Mayo de 2004), Coord. María José Salazar y Andrés Trapiello, p. 292. 
Las vestimentas, las actitudes, los gestos y los rasgos físicos (todos ellos objeto de estudio en las publicaciones científicas del momento) son los elementos que utiliza para crear sus tipos. Les arrebata el movimiento y su individualidad, colocándolos en una dimensión atemporal y por ello universal. Como vemos, Solana se apropió de los recursos y documentos que Parada y Santín había enseñado en sus clases pero con una finalidad radicalmente opuesta y diferente. Supongo que el destino se burlaba un poco de este maestro cuando el discípulo rebelde lo representó en El viejo profesor de Anatomía (fig.5) donde, arrebatándole su individualidad, ha quedado para siempre atrapado en un tipo, convertido en una figura tan "viva" como los moldes, láminas y libros que configuraron su mundo.

En resumen, podemos afirmar que el arte científico de Parada y Santín fue una propuesta que si bien materializaba el anhelo de un siglo fascinado por los descubrimientos científicos, subordinaba los aspectos formales a los intelectuales provocando que la obra de arte se convirtiera, en el mejor de los casos, en una "historia clínica visual". Sin embargo, es necesario enfatizar el hecho de que los materiales mostrados en los cursos de anatomía artística (cronofotografías, moldes antropológicos, estudios fisiológicos sobre la expresión) atrajeron a los jóvenes artistas que no dudaron en emplearlos en sus obras atendiendo a sus intereses particulares. De esta forma, la interrelación entre arte y ciencia se halla más que extendida en el siglo XIX y primeras décadas del XX. Por último, indicar que las contradicciones del discurso artístico de José Parada y Santín (tensión entre el material científico que muestra a los individuos como objetos de estudio y el fin del arte científico, esto es, lograr dar vida a las figuras) fueron puestas en evidencia y aprovechadas por José Gutiérrez Solana. Este último lograría extraer el potencial moderno de la teoría de Parada, eso sí, subvirtiendo radicalmente el sentido último de la pintura científica. 